\title{
REFLEXÕES SOBRE A CONSTRUÇÃO DE UMA PERSPECTIVA DE HUMANIZAÇÃO DAS PENAS ATRAVÉS DAS CONVICÇÕES DE DIOGO FEIJÓ
}

\section{REFLECTIONS ON BUILDING A HUMANE PERSPECTIVE OF} PENALTIES THROUGH CONVICTIONS BY DIOGO FEIJÓ

RESUMO: Padre Diogo Feijó se apresenta como um sacerdote regente de notoriedade tanto na seara política quanto religiosa, em especial, ao estabelecer o direcionamento da humanização das penas. Indaga-se assim se é possível a construção da ideia de uma pena humanizada através do exame das ideologias de Padre Feijó ainda no século XIX. O objetivo geral desta pesquisa almeja analisar as teses de Diogo Feijó que culminara com a constituição contemporânea da ideia de humanização das penas junto ao texto constitucional. Perfaz-se assim a aferição da gradativa consolidação da humanização das penas desde meados do século XIX quando Diogo Feijó discute a ideia de uma pena justa, direcionada pela legalidade como método de exclusão de arbitrariedades ao se condenar, de modo a trazer por consequência uma pena norteada pela humanização. Trata-se de uma pesquisa qualitativa realizada por meio de revisão bibliográfica que expõe as ideias de Diogo Feijó e como estas desembocam na ideologia de humanização das penas, apesentando-se através do método indutivo. Verifica-se assim que através do pensamento do Padre Feijó ocorreram alterações de convicções que denotam relevo que ecoam até os dias atuais, em especial, ante a consolidação do princípio da humanização das penas pela Constituição Federal de 1988.

Palavras-chave: Padre Feijó. Ideologia. Humanização das penas. Consolidação. Visão contemporânea. Constituição Federal de 1988.
ABSTRACT: Father Diogo Feijó presents himself as a regent priest with notoriety both in political and religious harvest, in particular in establishing the direction of humane penalties. It is asked if it is still possible the construction of the idea of humanizated penaltie through the examination of ideologies from Father Feijó even in the twenty-first century. The overall goal of this research seeks to analyse the thesis of Diogo Feijó that culminated with the contemporary constitution of the idea of humanization of penalties by the Constitution. Make up so gauging the gradual consolidation of the humanization of penalties since the mid- nineteenth century when Diogo Feijó discusses the idea of a just penalty, directed by legality as arbitrary exclusion method to be condemned, in order to bring therefore a sentence guided by the humanization. This is a qualitative research conducted through literature review that sets out the Diogo Feijó ideas and how they empty into the ideology of humanization of sentences, performing through the inductive method. It is thus that through the thought of Father Feijó that occured alteration of convictions that denote relevance which echoes to the present day, especially before the consolidation of the principle of humanization of penalties by the Federal Constitution of 1988.

Keywords: Father Feijo. Ideology. Humanization of feathers. Consolidation. Contemporary vision. Federal Constitution 1988.

${ }^{1}$ Professora da Faculdade de Direito do Centro Universitário Católica de Quixadá - Unicatólica. E-mail: semyfernandes@hotmail.com.

${ }^{2}$ Advogada. E-mail: andreakaram@uol.com.br. 


\section{INTRODUÇÃO}

A existência de um sancionamento lastreado pela observância da humanidade ao se punir mostra-se como ponto de discussão no âmbito do Estado brasileiro contemporâneo como uma garantia constitucional que, apesar de disposta na Constituição Federal de 1988 ainda não se encontra devidamente executado na realidade do aprisionamento.

Nesse sentido, a atuação política de Diogo Feijó como figura política do século XIX consistiu na expressão da defesa de circunstâncias aptas à refletir a consolidação de um mínimo de dignidade ao se punir com a privação da liberdade.

As teses defendidas pelo Padre Diogo Feijó no século XIX trouxeram a expressão de críticas e questionamentos que ainda ocasionam impactos relevantes no âmbito do Estado Democrático de Direito hodierno, demonstrando o quão extemporâneas se mostraram suas ideias. Dessa maneira, toma-se por problemática da pesquisa aferir a busca pela consolidação da ideia de humanização da pena através da ideologia de Diogo Feijó ainda no Brasil do século XIX.

Nesse contexto, apresenta-se como objetivo geral da presente pesquisa examinar a existência da construção de uma ideologia de pena dotada de humanização através das concepções do Padre Feijó, de modo a verificar quais as consequências de suas ideias no enquadramento social moderno, no que pertine ao exame do ius puniendi do Estado.

A análise da influência dos impactos da vida de Diogo Feijó na consolidação de suas teses, inicia-se pela exploração de sua infância precária, através do abandono de seus pais biológicos, seguindo pelo ingresso na vida eclesiástica para, por fim, tecer as considerações políticas de Diogo Feijó, ressaltando os seus ideais liberais, a sua luta no combate ao celibato clerical. Segue o artigo com as teses suscitadas por Feijó acerca da necessidade de observância da legalidade estrita, do devido processo e, por conseguinte da fixação de uma pena que apresentasse um mínimo de dignidade ao encarcerado.

Assim surge a discussão concernente à aferição da luta pela humanização das penas segundo Diogo Feijó, de modo que, mesmo entendendo o dever de punir diante de expressa 
violação normativa, Feijó pugnava pela definição sancionatória que se encontrasse norteada pelo mínimo de dignidade carcerária.

Os debates e a discussão da pesquisa traz à baila a discussão sobre a atuação de Padre Feijó com a propagação de propostas que ecoam pelo Brasil de hoje, ainda com tanta vivacidade, e que, com seus ideários humanizantes da pena, impactou na formação do pensamento constitucional brasileiro.

\section{RELATOS DA VIDA DE DIOGO ANTÔNIO FEIJÓ}

A análise da vida e obra que acompanham a trajetória de Diogo Antônio Feijó trazem impactos na consolidação de suas teses no cenário social brasileiro do século XIX, de modo que, para apresentar como Padre Feijó consegue difundir suas ideias no Brasil de outrora, necessário se mostra examinar quais as consequências que podem ser extraídas de sua vida pessoal e que repercutiram nas suas ideologias.

Homem de ideias fortes no campo político e passado triste na vida pessoal, eclesiástico de concepções diferenciadas, Padre Feijó se apresenta no contexto históricosocial brasileiro como um sacerdote detentor de princípios liberais que, apesar do discurso simples, conseguiu contaminar com suas teses o universo político-social no século XIX.

Nascido em 17 de agosto de 1784 em Itu, São Paulo, Diogo Antônio Feijó foi enjeitado por seus pais e deixado na porta da casa do Reverendo Fernando Lopes de Camargo ao nascer, vindo por este a ser criado e batizado no mesmo dia de seu nascimento (VIEIRA, 2010, p. 195).

Em sua certidão de batismo constara a definição de "filho de pais incógnitos", sendo a referida caracterização marca que o acompanharia por toda sua vida, sendo utilizado como ponto de críticas por seus opositores políticos (SOUZA, 1942).

Destarte, sua desconhecida filiação, que lhe negara um sobrenome, não lhe excluíra o direito à uma vinculação familiar afetiva, haja vista que em seus documentos resta expresso o nome do padre Fernando Lopes de Camargo como seu padrinho de batismo (CALDEIRA, 1999, p. 21).

Quanto às origens familiares de Diogo Feijó, inicialmente supunha-se que o mesmo seria filho da irmã do padre Fernando Camargo, Maria Gertrudes Camargo, sendo Feijó filho 
uma relação espúria da viúva de Miguel João Feijó (Gertrudes) com um parente próximo do mesmo, Félix Antônio Feijó (ELLIS JÚNIOR, 1940, p. 37).

Contudo, apesar da inexistência de registros formais sobre os possíveis pais biológicos de Feijó, meio século após sua morte trouxeram-se esclarecimentos sobre sua filiação, de modo que possivelmente seria filho de Maria Joaquina Soares de Camargo, a outra irmã do padre que criara Feijó, tendo esta dado à luz ainda na mocidade e solteira, vindo a conviver com o filho biológico quando este fora acolhido por seu irmão (VIEIRA, 2010, p. 196).

Quanto ao pai biológico de Diogo Feijó, estima-se que seria um vigário de Cotia, Manuel da Cruz Lima (VIEIRA, 2010, p. 196). Contudo, as indefinições sobre os pais de Diogo Feijó nunca viabilizaram a emissão de dados concretos neste aspecto da vida do padre regente, sendo fato que Feijó jamais fizera referência a sua verdadeira origem e sempre se reportou a sua mãe biológica como mãe de criação (CÂMARA NETO, 2012, p. 1).

Conseguiu estudar por conta própria até atingir a idade adequada para ordenar-se. Através de seu esforço conquistou a possibilidade de lecionar como meio de sustento, o que Ihe propiciou sobreviver, exercendo o magistério na cidade de Guaratinguetá, Parnaíba e Campinas, onde ministrou aulas de francês, latim, história, geografia e português, instruindo-se ainda em filosofia, o que lhe viabilizou o contato com as convicções kantista (REIS, 2015, p. 3).

Com sacrifício Diogo Feijó ordenara-se padre em 1805, se submetendo a comprovação do critério de origem familiar proba de forma bastante sui generis, pois desconhecia sua origem biológica. Assim, procurando vencer a dificuldade de comprovação de "idoneidade familiar" como requisito para a ordenação, lavrou declaração atestando que não repetiria o abandono feito por seus genitores (CALDEIRA, 1999, p. 23).

Apesar de ordenado padre, o que amenizava o estigma de "filho bastardo", Diogo Feijó ainda possuía precárias condições econômicas, vindo estas a melhorar quando o Padre foi designado presbítero em 1808 (CALEIRA, 1999, p. 23).

Em 1817 Diogo Feijó recebeu uma herança de sua avó, o que lhe trouxe notoriedade junto a sociedade campinense que passara a deixar de qualificá-lo como simples clérigo para tratá-lo segundo sua aquisição patrimonial como "senhor de engenho" (CALDEIRA, 1999, p. 25). 
Quanto a sua atuação como clérigo, Feijó iniciara seu ofício na cúria, contudo, pouco tempo depois foi designado a cumprir suas atividades eclesiásticas em Guaratinguetá, em Parnaíba e por fim, em Campinas. Em seguida, mudou-se para Itu, onde desenvolveu atividades junto à agricultura com os escravos (ELLIS JÚNIOR, 1940, p. 56).

Padre Feijó resolveu ainda estruturar seu próprio colégio interno, passando a ministrar neste as disciplinas de filosofia, lógica e moral, vindo a ganhar destaque ante sua personalidade de clérigo detentor de práticas contidas e idoneidade moral (ELLIS JÚNIOR, 1940, p. 56).

A atuação de Feijó passa a ganhar relevo quando o referido padre tende a difundir a ideia de separação do Brasil de Portugal, vindo a trazer as primeiras manifestações do seu posicionamento político (ELLIS JÚNIOR, 1940, p. 56).

Na política Diogo Feijó ganhou notoriedade junto a sociedade brasileira do século XIX, iniciando sua carreira política ainda em Itu como vereador. Em 1821 tornou-se Deputado brasileiro às Cortes em Lisboa por São Paulo, possuindo fundamentos separatistas, e sendo, em face destas circunstâncias, perseguido e vindo a refugiar-se na Inglaterra. Feijó negou-se a assinar a Constituição Portuguesa que continuava a reduzir a nação brasileira a uma simples colônia sem autonomia (JUCÁ, 2008, p. 61).

Feijó retornaria para o Brasil após seu exílio inglês apenas com a independência brasileira, se apresentando como político que muito contribuiu na elaboração da Constituição Imperial de 1824, pois fora o mesmo uma das raras figuras políticas a tecer críticas ao Conselho de Estado (JUCÁ, 2008, p. 61).

Buscando traçar na Constituição Imperial feições liberais, Feijó desencadeou reflexões sobre o Projeto da Constituição, emitindo estas diretamente ao Imperador e dando destaque aos seus ideários, advindos diretamente da Câmara de Itu ao paço imperial (BONAVIDES; ANDRADE, 1991, p. 79).

Em 1826 Diogo Feijó torna-se Deputado Geral por São Paulo, vindo em seguida a ser nomeado Ministro da Justiça pela Regência Trina Permanente em 1831, mesmo após ter coordenado o movimento em prol da abdicação do Imperador D. Pedro I. No cargo de Ministro da Justiça o mesmo buscou controlar as principais insurreições revolucionárias da época, bem como os conflitos entre exaltados e restauradores (JUCÁ, 2008, p. 62). 
Como Ministro da Justiça, Feijó repreendeu a desordem através da vedação de anistia aos rebeldes (VIANNA, 1994, p. 458). Destacou-se ainda a atuação do Padre Feijó junto ao Ministério pela constituição da Guarda Nacional, sendo esta composta por civis. Feijó apresentou o reestabelecimento da ordem e a exclusão de prisões arbitrárias ou ilegais, traçando o suporte para a observância da legalidade estrita na imposição da sanção penal (JUCÁ, 2008, p. 63).

Em face de suas ideias liberais Padre Feijó adquiriu várias inimizades, dentre estas sérias animosidades com José Bonifácio Andrada e Silva, inimigo declarado do clérigo e contra quem Feijó conspirou a destituição da tutoria de D. Pedro II em 1832, ao propor o rechaçar de Bonifácio a Câmara dos Deputados.

A antipatia de Feijó a Bonifácio não advinha de simples desavenças, mas sim, ante a existência de discursos conservadores de José Bonifácio o que, segundo o Padre Feijó, representava de riscos a implementação de teses liberais em solo brasileiro (JUCÁ, 2008, p. 64).

Feijó é designado Senador pelo Rio de Janeiro em 1833, vindo no ano subsequente a fundar o jornal O Justiceiro, que circulou entre 1834 e 1835 . O referido jornal tinha por objetivo difundir no cerne social brasileiro do século XIX os ideais liberais que traziam ainda temáticas dotadas de polêmica, como a questão da abolição do celibato (JUCÁ, 2008, p. 64).

Em 1835 Feijó é eleito o primeiro representante do Executivo escolhido em uma eleição nacional, tendo sido designado como regente uno. Vê-se que o dia 7 de abril de 1835 seria um marco histórico da participação popular nas atividades políticas, pois pela primeira vez ocorreu uma eleição nacional para escolha do chefe do Executivo. Assim sendo, o nomeado passaria a representar o Imperador D. Pedro II até a maioridade (CALDEIRA, 1999, p. 11).

Contudo, Feijó opta por renunciar a regência una em 1837, tendo em vista a eclosão de diversos motins em todo o território nacional, de modo que as diversas revoltas trouxeram instabilidade política que não tiveram como ser suportadas pelo padre (CALDEIRA, 1999, p. 11).

Padre Feijó retorna ao cenário político brasileiro em 1842, já debilitado e em cadeira de rodas. Figurou como líder na Revolução Liberal de São Paulo, onde continuou a difundir a 
defesa da ordem legal, de modo a expor a necessidade da observância à estrita legalidade. Contudo, Feijó não logrou êxito em seu intento revolucionário, vindo a ser derrotado e preso.

Diogo Feijó faleceu em São Paulo, em 10 de novembro de 1843 aos 59 anos. Contudo, não se pode descurar a vultosa contribuição de Feijó no campo político como defensor da descentralização e do liberalismo e que, passou a propagar polêmicas discussões religiosas sobre o fim do celibato clerical.

\section{O CELIBATO CLERICAL SEGUNDO PADRE FEIJÓ}

Diogo Feijó apresentara discussões e polêmicas não só no cenário político, mas também nos contornos religiosos, em especial, quanto as questões acerca do celibato clerical, apresentando assim opinião distinta de grande parte dos clérigos do séculos XIX.

Um dos pontos que suscitou o combate ao celibato clerical por Diogo Feijó consistiu no fato de ser o mesmo descendente espúrio de um clérigo, de modo que a frustração advinda de uma filiação ilegítima despertara no mesmo a luta pela abolição ao celibato clerical (ELLIS JÚNIOR, 1940, p. 115).

A discussão em torno do anticelibato passou a ganhar expressividade a partir de 1827, quando o Deputado liberal Antônio Ferreira França expusera como sugestão que os clérigos tivessem direito ao casamento, sendo apoiado por Diogo Feijó que vem a atribuir repercussão a temática (OLIVEIRA, 2015).

Interessante destacar que a discussão desencadeada por Ferreira França trouxe à lume questão já conhecida junto ao clero, não denotando qualquer novidade, contudo, apenas se atribuiu publicidade a questões corriqueiras que consistia nas relações de coabitação envolvendo clérigos (CÂMARA NETO, 2015).

Em 1827 Feijó passa a defender a abolição do celibato, difundindo tal ideologia através do lançamento do folheto Demonstração da necessidade da abolição clerical pela Assembleia Geral do Brasil (CÂMARA NETO, 2015).

Atraídos pelas teses polêmicas de Feijó acerca do anticelibato, muitos dos opositores do celibato começaram difundir a ideia do celibato como meio de manutenção de relações 
espúria, de modo que a extirpação do celibato traria decência a um clero marcado pela mancebia.

Diogo Feijó entendia que a abolição do celibato clerical viria a propiciar a formalização do matrimônio pelos sacerdotes, entendo que a existência da vida conjugal consistiria em direito ínsito ao homem e, em face de tal intento, possuía um caráter divino (JUCÁ, 2008, p. 75). Ressaltava Feijó que a lei do celibato carregava consigo a tendência ao descumprimento por ser oposta a natureza humana.

Os sacerdotes liberais, encabeçados por Feijó, defendiam o anticelibato como uma questão religiosa a ser discutida na perspectiva política. Deste modo, surgem as primeiras expressões de reforma católica no Brasil, ao apresentar, segundo a política regalista, o surgimento de uma Igreja brasileira que detivesse desvinculação a doutrina papal em Roma (CÂMARA NETO, 2015).

O regalismo consistia em uma doutrina que possibilitava ao chefe de Estado intervir nas discussões religiosas, ganhando força no Brasil Império como continuidade do pombalismo português. O regalismo trazia a possibilidade de discussões acerca do celibato clerical no âmbito da Assembleia, pois tais questões seriam de interesse do Estado de modo que a vida religiosa deveria se adequar aos anseios da coroa (VIEIRA, 2010, p. 194-195).

A participação de clérigos no cenário político brasileiro da época era corriqueiro, haja vista que grande parte da Assembleia era composta por sacerdotes.

Incitados pela discussão sobre o celibato clerical, as opiniões se dividiram. Como apoiadores do anticelibato, encabeçados por Diogo Feijó, figuravam Amaral Gurgel, Idelfonso Xavier Ferreira, Marcelino Ferreira Bueno dentre outros.

Em contraposição, Dom Romualdo Antônio de Seixas, arcebispo baiano e Deputado, figurou como defensor da ideia de um clero atuante e que fosse subserviente ao celibato. Sustentava que questões religiosas não deveriam ser discutidas pelo o Estado (CÂMARA NETO, 2015). Dom Romualdo era acompanhado na defesa ao celibato por Dom Marcos de Souza, Padre Luiz Gonçalves dos Santos (conhecido popularmente como Padre Perereca) e o Visconde do Cariú.

Contudo, o império do conservadorismo triunfou. Os defensores do celibato clerical na Assembleia vêm a preponderar, de modo que, com o apoio da Igreja através do auxílio da 
Santa Sé, a manutenção do celibato restou consolidada, apesar das insistências do Padre Feijó em afastar tal regramento.

Padre Feijó demonstra que não apenas no âmbito político figurava como um homem de opiniões avançadas, pois o fato de ser sacerdote jamais se manifestou como óbice para que o mesmo se apresentasse como opositor do celibato clerical (JUCÁ, 2008, p. 74).

O fato de ser um padre avesso aos elementos da lei do celibato clerical não se apresentou como obstáculo para que o Padre Feijó fosse escolhido pela maioria dos brasileiros na primeira manifestação seletiva por pleito eleitoral no Brasil como representante do Imperador D. Pedro II na regência una (CALDEIRA, 1999, p. 29).

\section{A COLABORAÇÃO DE DIOGO FEIJÓ NO PENSAMENTO POLÍTICO BRASILEIRO}

A atuação do Padre Diogo Feijó na esfera política ainda repercutem no âmbito constitucional contemporâneo, apesar de consistir em ideias que surgiram em uma sociedade ainda acanhada no que tange à democracia.

Os estudos, escritos e manifestações deixados por Padre Feijó mostram o quanto os problemas sociais que assolavam o Brasil do século XIX ainda encontram expressividade na atualidade.

Mesmo enfrentando ferrenha oposição conservadora, Feijó defendia a sedimentação da igualdade, da justiça, da democracia e da consolidação de uma ordem constitucional com ideários liberais. Assim, como representante dos fundamentos progressistas liberais, Feijó intervinha em favor do dever de observância aos preceitos na Constituição (JUCÁ, 2008, p. 67).

Feijó ganhou destaque quanto às ideias políticas, pois defendia a proteção de convicções democráticas, igualitárias, primando pela preponderância da legalidade, bem como pela liberdade política e pela emancipação nacional (JUCÁ, 2008, p. 68).

As ideias de Diogo Feijó podem ser consideradas como uma manifestação política extemporânea, conflitando-se com os conceitos dominantes no Brasil do século XIX, ao defender ideias liberais que repercutem no cenário constitucional brasileiro contemporâneo (JUCÁ, 2008, p. 68). 
Feijó entendia que o Brasil deveria ser uma nação onde a liberdade deveria imperar e que em face de tal intento, a norma constitucional teria de garantir o direito do homem a ser livre (CALDEIRA, 1999, p. 14).

Segundo a filosofia moral de Feijó, a liberdade pode ser entendida como a expressão de uma vontade dotada de freios, apresentando caracteres de uma liberdade negativa, pois, a liberdade traria a necessidade de regulamentação da vontade, sendo o direito de ser livre ausente de paixões, consistindo, portanto no exercício da racionalidade (COELHO, 2011, p. 135).

O destaque constante a necessidade de observância dos regramentos constitucionais fora uma das teses defendidas por Feijó, traçando as primeiras diretrizes do que se denominou de princípios básicos da Teoria Constitucional, que traz o dever de fidelidade a norma disposta na Constituição (JUCÁ, 2008, p. 69).

Diogo Feijó pugnava ainda pelo combate à discriminação em desfavor de pobres e índios, ao afastamento da vitaliciedade do cargo de Senador, à Monarquia, à violação aos mandamentos legais, pois entendia que tais fatores destruíam a imparcialidade (JUCÁ, 2008, p. 69).

Destacou-se ainda por suas concepções avançadas na questão do federalismo, propagando o direito à autonomia parlamentar na província. Feijó fazia com que a conjuntura política brasileira de sua época travasse discussões que pudessem trazer mudanças para sociedade, ao propagar um pensamento liberal.

Padre Feijó traçou críticas à administração da justiça e a forma de se julgar, desaprovando os arranjos de decisões que não traziam a imparcialidade do julgador, mas expunha os vícios de uma sociedade marcada pela troca de interesses. Em face de suas críticas Feijó traça as primeiras diretrizes do que ganharia tutela constitucional através da moralidade, da imparcialidade e dos norteios do acesso à justiça (JUCÁ, 2008, p. 69).

Através do jornal $O$ Justiceiro Diogo Feijó expunha suas ideias liberais, deixando registros de suas concepções quanto à separação dos poderes, aos princípios da Administração Pública, à prevalência do dever de submissão à legalidade, bem como em diversos direitos fundamentais, que hoje se encontram, garantidos pela Constituição Federal Brasileira de 1988 (JUCÁ, 2008, p. 71). 
Feijó compreendia que o cumprimento dos regramentos legais traria o afastamento da impunidade quanto aos crimes praticados por pessoas que detivessem influência social, bem como excluiria a existência de prisões arbitrária, como decorrência de um devido processo (JUCÁ, 2008, p. 71).

Quando à frente do cargo de Ministro da Justiça durante a regência trina e no período da regência una, Diogo Feijó combateu com firmeza os motins sociais, tendo, inclusive, restado por formalizada condenações duras. Contudo, tais condenações ocorreriam dentro da lei, de modo que nenhum desconhecido restara preso sem a submissão ao devido processo (CALDEIRA, 1999, p. 32-33).

Nessa entoada, bem se pode aferir que Diogo Feijó, ao defender a condenação com base no prévio processo punitivo, lança as diretrizes de um dos princípios constitucionais com relevantes impactos no processo penal atual, qual seja, o devido processo legal.

A atuação de Diogo Feijó na esfera política trouxe melhorias, tais como, o afastamento de prisões ilegais ante a inexistência de culpa, a fixação de responsabilidade do magistrado quanto ao descumprimento dos prazos das prisões, melhora nas condições dos apenados, afastamento da confissão sob tortura e responsabilização dos senhores de escravos que praticassem a violência como forma de castigo (CALDEIRA, 1999, p. 33).

As propostas de Padre Feijó teria portanto como traços característicos a existência do compromisso com a ordem social, com na inclinação liberal, no afastamento a violação de regramentos, bem como no prevalência dos mandamentos legais (PIÑEIRO, 2015).

Assim, mesmo existentes dificuldades advindas dos conflitos das teses de Feijó e dos conservadores, não se pode descurar que o mesmo conseguiu apresentar as bases de um novo modelo constitucional brasileiro, culminando com a gradativa consolidação de concepções que acompanham a ordem democrática constitucional moderna.

\section{A IDEIA DE HUMANIZAÇÃO DAS PENAS NAS PERSPECTIVA DE DIOGO FEIJÓ}

Diogo Feijó apresenta um pensamento avançado (para) ao seu tempo. Tal assertiva não se restringe ao fato de sua postura política ser pautada em um ideal liberal, nem tampouco por ter defendido a ideia de um anticelibato em uma sociedade ainda regida pelos ditames religiosos, mas por propagar a ideia de observância à legalidade estrita, ao 
devido processo legal, do afastamento de arbitrariedades ao se punir, defendendo ainda a necessidade de se fornecer ambientações adequadas ao cumprimento da pena.

Nessa entoada, verifica-se que Padre Feijó defendia o afastamento de prisões arbitrárias, bem como primava pela fixação sancionatória que afastasse o degredo carcerário, de modo a difundir um mínimo de humanidade na imposição punitiva.

Dessa maneira, detecta-se no pensamento de Diogo Feijó as primeiras expressões punitivas em solo nacional que apresentaram a relevância da humanização da pena. Tal característica, ínsita a imposição punitiva, revela sua importância no contexto social atual sendo tutelada pela Constituição Federal de 1988, mais precisamente no art. 50, incisos III, XLVII, XLIX.

Nesse sentido, depreende-se que a pena dotada de humanidade, conforme as diretrizes hoje presentes no texto constitucional brasileiro e outrora difundidas nas ideias de Diogo Feijó, consistem na imposição de penas que afastam o degredo da execução da pena, que deixa de tratar o agente delitivo como uma escória e passa a observá-lo como sujeito de direitos (MARACAJÁ, 2016).

Assim sendo, o princípio da humanidade consiste na expressão de decretação de inadmissibilidade, segundo a ordem constitucional hodierna, de qualquer sancionamento que crie um impedimento físico permanente (morte, amputação, castração ou esterilização, intervenção neurológica etc.) (ZAFFARONI; PIERANGELI, 1999).

Ao deliberar através dos dispositivos presentes na Constituição Federal de 1988 a expressão do princípio da humanidade como corolário da dignidade humana, estar-se-ia por afastar a sanção cruel, desumana ou degradante, bem como o emprego de métodos de tortura, de modo que implica em dever do Estado contemporâneo zelar pelo afastamento das mazelas do cárcere e buscar recuperar o agente delitivo (MARACAJÁ, 2016).

Perpassando assim a análise da ideia atual de pena humanizada, verifica-se os primeiros vestígios desta no plano social brasileiro ainda no século XIX quando Diogo Feijó começa a expor críticas acerca da penúria em que se encontravam suscetíveis os apenados.

Destarte, Feijó passa a destacar a necessidade de um efetivo investimento estatal para viabilizar o direito a uma pena tolerável, haja vista que a formalização da prisão em 
calabouços que apresentavam condições insalubres se mostrara como expressão sancionatória tirânica (CALDEIRA, 1999, p. 90).

Observa-se assim que de forma ainda tímida Feijó começa a propagar a existência de humanidade das penas segundo as diretrizes traçadas pelos ideários iluministas de Cesare Beccaria, pois, segundo este, haveria uma falsa percepção de segurança social ao se punir de forma desmedida e sem observar os ditames legais, o que tende a afastar a humanidade punitiva (BECCARIA, 2002).

Feijó suscita ainda apreciações acerca do fornecimento de verbas para a construção de ambientes carcerários mais humanos, de modo a se contrapor aos valores ínfimos despendidos pelo Estado com gastos para a prisão. Assim, segundo Feijó, a prisão deve ser imposta ao delinquente, mas desde que expressa mediante a existência de um estabelecimento prisional que não viesse a excluir a dignidade humana do prisioneiro.

Para o Padre Feijó a aplicação sancionatória não deve ser afastada do criminoso, mas, a imposição punitiva deve se dar em consonância com a proporcionalidade em face do crime. Assim, como decorrência da humanidade da pena, necessário se mostra a aferição da pena proporcional ao dano causado (CALDEIRA, 1999, p. 90-91).

Destacava o Padre Feijó a fixação punitiva, mas, a sanção deveria se apresentar passível de execução, de modo que ao prisioneiro dever-se-ia fornecer a possibilidade do direito à um mínimo de humanidade na execução punitiva, sendo incumbência do Estado, segundo o Padre Feijó propiciar a existência de previsão orçamentária que viesse a proporcionar a sanção adequada (CALDEIRA, 1999, p. 90-91).

Assim, como expressão contemporânea da consolidação da humanização das penas no plano constitucional, verifica-se que deve restar por afastada qualquer argumento moral apto a legitimar o Estado a matar, torturar, humilhar o cidadão, mesmo que este viole a norma e venha a delinquir (FERRAJOLI, 2014, p. 364).

Mais uma vez, Diogo Feijó se adianta ao seu tempo, de modo que a discussão concernente à humanidade da pena denota destaque na atualidade carcerária brasileira do século XXI, haja vista que o colapso punitivo não consistia apenas em problemática inerente a sociedade brasileira do passado, mas, persiste de forma latente nos contextos punitivos atuais, mesmo após a consolidação constitucional do direito à pena digna como princípio 
constitucional implícito e derivado do fundamento da dignidade da pessoa humana (GRECO, 2015).

Impende destacar que a difusão do ideário de pena humanizada defendida por Diogo Feijó ainda no século XIX consistiria nas bases iniciais da humanização das penas no contexto constitucional contemporâneo, mas que não descurava as características ínsitas ao sancionamento presente no século XIX e que não encontram expressividade atual ante a vedação pela Constituição Federal de 1988 de diversas sanções outrora admitidas, tais como penas de castigos físicos.

Dessa maneira, verifica-se que a ideia de humanização das penas suscitada por Padre Feijó, vincular-se-ia à discussão das condições do cárcere, das situações a que os apenados sujeitos à pena privativa de liberdade se encontravam expostos.

Vislumbra-se, portanto, que a intervenção do Padre Feijó ansiava pela punição baseada no respeito aos regramentos legais e com a imposição de uma prisão com mínimas condições de existência, isso tomamos como avanço às ideias do século XIX. Verifica-se assim que suas ideias ainda se refletem no ideário constitucional contemporâneo, através da ideologia de pena humanizada que encontra guarida constitucional na atualidade.

\section{CONCLUSÃO}

Através do exame das teses defendidas pelo Padre Diogo Feijó, concluiu-se pela expressividade das convicções concernentes a constituição de uma perspectiva de humanização das penas no âmbito social brasileiro do século XIX o que, por conseguinte, culminam com a manifestação do princípio da pena humanizada no atual contexto social.

Depreende-se assim do presente estudo que Padre Feijó constituiu-se em uma figura emblemática na historiografia brasileira, haja vista que o mesmo apresentara contribuições de relevo em diversas searas da sociedade brasileira de seu tempo.

Nesse sentido examinou-se que a realidade de uma vida pessoal marcada por abandonos não fora um empecilho para que Diogo Feijó lograsse êxito nos caminhos que traçara junto ao exercício sacerdotal, mesmo diante de diversos preconceitos que se encontravam envoltos dos filhos oriundos de relacionamentos espúrios, como o caso de Feijó. 
As polêmicas considerações de Feijó acerca da vida sacerdotal fizera com que o Padre Feijó defendesse a abolição do celibato clerical, tendo em vista o fato de ser filho bastardo de um clérigo.

$\mathrm{Na}$ seara política relevantes foram as contribuições de Diogo Feijó, deixando seu registro na busca pela igualdade, pela implementação da democracia, nos primeiros passos de uma tese federalista, na luta em favor da ordem social, no combate ao despotismo e a corrupção, no combate pela implementação da moralidade e imparcialidade estatal, ganhando destaque ainda pela defesa da legalidade.

Confere-se assim expressão a sua ideologia na busca da pena dotada de humanidade e, tal intento, segundo defendido por Feijó, deveria se iniciar ainda na fase investigativa, de modo a destacar a defesa do direito de todos a um devido processo legal, afastando, pois, a existência de prisões ilegais e arbitrárias.

Na perspectiva carcerária, Padre Feijó pugnou pela humanidade punitiva, de modo a entender pelo afastamento da condição de degredo carcerário, pois, segundo Feijó, os violadores da norma deveriam receber o sancionamento que lhes era devido, mas a punição não poderia se delinear em condições degradantes.

Nessa vertente, aferiu-se que Padre Diogo Feijó já expunha em sua época o que se compreende no atual contexto por direito à pena digna, que se manifesta como ramificação da dignidade da pessoa humana, um dos fundamentos básicos da ordem democrática que integra a Constituição Democrática de 1988.

Contudo, leva-se ao desfecho de que a implantação da humanização sancionatória outrora agasalhada nas teses do Padre Feijó integra o pensamento constitucional hodierno de modo sólido, apesar da inefetividade de execução desta ante a crise carcerária contemporânea.

\section{REFERÊNCIAS}

BECCARIA, Cesare. Dos delitos e das penas. São Paulo: Martin Claret, 2002. 
BONAVIDES, Paulo; ANDRADE, Paes de. História Constitucional do Brasil. 3 ed. Rio de Janeiro: Paz e Terra, 1991.

CALDEIRA, Jorge. Diogo Antônio Feijó, 1784-1843. São Paulo: Editora 34, 1999.

CÂMARA NETO, Isnard de Albuquerque. Feijó de Clérigo a Regente, as relações Igreja e Estado. Anais do XXI Encontro Estadual de História, Campinas, 2012. Disponível em: < http://www.encontro2012.sp.anpuh.org/resources/anais/17/1341079432_ARQUIVO_Padre Feijo.pdf>. Acesso em: 02 nov. 2015.

- 0 padre Feijó e a questão do celibato clerical. Disponível em: <http://site.unitau.br/scripts/prppg/humanas/download/opadrefeijo-N2-2001.pdf>. Acesso em: 20 nov. 2015.

COELHO, Humberto Schubert. A filosofia moral de Diogo Feijó. Revista Estudos Filosóficos, São João Del-Rei, n. 7, p. 132-138, 2011. Disponível em:

<http://www.ufsj.edu.br/portal2repositorio/File/revistaestudosfilosoficos/art12_rev7.pdf>. Acesso em: 18 out. 2015.

ELLIS JÚNIOR, Alfredo. Feijó e sua época. São Paulo: EdUSP, 1940.

FAUSTO, Boris. História do Brasil. 8. ed. São Paulo: Fundação do Desenvolvimento da Educação, 2000.

FERRAJOLI, Luigi. Direito e Razão: Teoria do garantismo penal. Tradução de Ana Paula Zomer Sica; Fauzi Hassan Choukr; Juarez Tavares; Luiz Flávio Gomes. 4. ed. São Paulo: Revista dos Tribunais, 2014.

GRECO, Rogério. Sistema prisional: colapso atual e soluções alternativas. 2ạ ed. Rio de Janeiro: Impetus, 2015.

JUCÁ, Roberta Laena Costa. Padre Antônio Diogo Feijó: O pensador da liberdade. In: LIMA, Martônio Mont'Alverne Barreto et al (Orgs.). Temas de pensamento constitucional brasileiro. Fortaleza: EdUFC, 2008, p. 60-78.

MARACAJÁ, Luciano de Almeida. O Estado Democrático de Direito e o princípio da humanidade. Disponível em: < http://www.juristas.com.br/informacao/artigos/o-estadodemocratico-de-direito-e-o-principio-da-humanidade/1828/>. Acesso em: 10 ago. 2016.

OLIVEIRA, Gabriel Abílio de Lima. Liberalismo e Religião no Império Brasileiro: O Período Regencial (1831-1840). Anais do XXVIII Simpósio Nacional de História, Florianópolis, 2015. Disponível em:

<http://www.snh2015.anpuh.org/resources/anais/39/1427759981_ARQUIVO_ArtigoANPUH .pdf>. Acesso em: 23 nov. 2015.

PIÑEIRO, Théo Lobarinhas. Feijó: entre a justiça e a prudência? Disponível em: < http://www.historia.uff.br/estadoepoder/6snepc/Mesas/mesa8-Th\%C3\%A9o.pdf>. Acesso em: 23 nov. 2015.

REIS, Luis Fernando Scherma. Diogo Antônio Feijó - O primeiro mandatário eleito no Brasil Imperial. Anais do XXIV Congresso Nacional do Conpedi, Aracaju, 2015. Disponível em: < http://www.conpedi.org.br/publicacoes/c178h0tg/405y7512/0ahvJ7j95oskj0d9.pdf >. Acesso em: 16 nov. 2015. 
RICCl, Magda Maria de Oliveira. Assombrações de um padre regente: Diogo Antônio Feijó (1784-1843). Campinas: EdUNICAMP, 2002.

SOUZA, Octávio Tarquinho de. Diogo Antônio Feijó (1784-1843). Rio de Janeiro: José Olympio, 1942.

TALASSI, Luiz A. A doutrina do Padre Feijó e suas relações com a Sé Apostólica. Roma: Pontifícia Universidade Gregoriana, 1949.

VIANNA, Hélio. História do Brasil. 15 ed. São Paulo: Companhia dos Melhoramentos, 1994. VIEIRA, Dilermando Ramos. Padre Antônio Diogo Feijó: as controvérsias de um sacerdote regalista e anticelibatário. Revista Pistis Praxis, Curitiba, v. 2, n. 1, p. 193-210, jan/jun., 2010. Disponível em: < file://C:/Users/Meus\%20Documentos/Downloads/pistis-3554\%20(4).pdf>. Acesso em: 23 nov. 2015.

ZAFFARONI, Eugenio Raúl; PIERANGELI, José Henrique. Manual de Direito Penal Brasileiro: parte geral. 2. ed. São Paulo: Revista dos Tribunais, 1999.

TOMÉ, Semiramys Fernandes; KARAM, Andrea Maria

Sobreira. Reflexões sobre a construção de uma

perspectiva de humanização das penas através das

conviç̧ões de Diogo Feijó. RBSD - Revista Brasileira de

Sociologia do Direito, v. 3, n. 2, p. 214-230, mai./ago.

2016.

Recebido em: 25/07/2016

Aprovado em: 09/08/2016 